\title{
Understanding volunteer motivations to participate in citizen science projects: a deeper look at water quality monitoring
}

\section{Bethany Alender}

\begin{abstract}
Volunteer water quality monitors represent the intersection between citizen science and environmental stewardship. Understanding what motivates participation will enable project managers to improve recruitment and retention. This survey of 271 volunteers from eight water quality monitoring organizations in the U.S. found the strongest motivators to participate are helping the environment or community and contributing to scientific knowledge. No variation by gender was found, but younger volunteers have different motivations and preferences than older volunteers. Volunteers value the communication of tangible results more than recognition or reward.
\end{abstract}

Keywords

Citizen science; Public engagement with science and technology; Public perception of science and technology

Citizen science projects generally have several overlapping goals that yield benefits in three major categories: outcomes for scientific research such as data collection, outcomes for participants including education and new skills, and outcomes for social-ecological systems like conservation, stewardship, and policy [Dickinson and Bonney, 2012; Shirk et al., 2012]. Because resources are limited, citizen science projects make trade-offs between their goals of research, education, and stewardship [Dickinson and Bonney, 2012], which may reduce the project's ability to tackle complex issues [Shirk et al., 2012]. Previous studies have found that many volunteers have complex motivations that connect to all three of these overlapping missions. For example, Clary et al. identified motivations in six categories: (1) values - altruism and concern for others, (2) understanding, (3) social, (4) career, (5) ego protective - escape from negative feelings, and (6) ego enhancement - personal growth and self-esteem [1998]. While these motivations may not be exhaustive for citizen science, Clary et al. established a framework for assessing movitations, known as the Volunteer Functions Inventory, and also revealed an essential element of volunteer retention: volunteers reported intent to continue volunteering when they received benefits relevant to their primary motivations [Clary et al., 1998].

Volunteers are the backbone of citizen science projects. Although they offer a cost-effective way to collect more data than scientists could collect on their own, 
volunteers are not free labor: "Financial and human resources are required to recruit, train, supervise, and retain volunteers and to recognize their accomplishments" [Jacobson, Carlton and Monroe, 2012, p. 53]. Understanding volunteer motivations will help project managers reduce recruitment and retention costs and maximize the benefits derived from volunteerism [Jacobson, Carlton and Monroe, 2012; Raddick et al., 2010; Shirk et al., 2012]. Such information may help managers address two major challenges for citizen science projects: program organization and collection of rigorous data [Conrad and Hilchey, 2011].

At the organizational level, the main challenges to citizen science projects include funding and volunteer recruitment [Conrad and Hilchey, 2011]. These two issues may be reinforcing since funding is needed to recruit volunteers and volunteer participation is often needed to attract funding [Dickinson and Bonney, 2012]. Understanding volunteer motivations to participate is a critical element of producing a successful citizen science project.

Many citizen science projects and water quality monitoring projects are data intensive. Citizen science volunteers might be motivated to participate by how data is used for ecosystem management or scientific publications. For example, in the study by Roggenbuck et al. [2001], volunteers stated that they wanted more feedback from coordinators about how the data is used and they wanted increased use of data by government agencies. However, the scientific and government communities struggle to trust citizen science data for several reasons: data may be subjected to fragmentation, inaccuracy, lack of objectivity, poor experimental design, and inadequate sample size [Conrad and Hilchey, 2011]. Some scientists and government agencies do not have confidence in the level of training volunteers receive. In contrast to these concerns, research shows that volunteer-collected data can be comparable to data collected by trained professionals with validation and calibration [Conrad and Hilchey, 2011]. Better understanding of volunteer motivations related to the communication and use of scientific knowledge might provide guidance for program managers concerned with improving the reliability of data collection.

Volunteer project outcomes are influenced by both quantity and quality of participation [Shirk et al., 2012]. Quantity of participation reflects the number of participants and how much time they spend participating. Many funders focus on this aspect because it provides a measurable and comparable index of organizational success. However, Shirk emphasizes the value of focusing on the quality of the volunteer experience. Quality of participation reflects "the extent to which a project's goals and activities align with, respond to, and are relevant to the needs and interests of public participants" [Shirk et al., 2012, p. 4]. When the interests of the participants are woven into the design of the project, high quality participation follows because the volunteers' values are being expressed; if the quality of participation is carefully cultivated, then increased quantity of participation can lead to enhanced outcomes. Thus taking volunteer motivations into account can increase both the quantity and quality of participation and improve the ability of the project to meet its goals [Shirk et al., 2012]. 
This study examines citizen science volunteers that engage in water quality monitoring. Water quality monitoring is well-established in the United States, with approximately 1,800 volunteer groups represented in the National Volunteer Water Monitoring Program Directory as of 2013 [Volunteer Water Monitoring and Master Naturalist Programs in the US, 2013]. The Environmental Protection Agency is pushing state agencies to increase the number of water bodies assessed in their reports to Congress, yet these agencies are typically understaffed [Addy et al., 2010]. Thus, volunteer water quality monitoring programs provide recognized value to society while also engaging the public in watershed protection and enhancement [Addy et al., 2010]. An estimated 8,500 volunteers across the U.S. monitor all types of water bodies including rivers, streams, lakes, ponds, wells, wetlands and estuaries [Overdevest, Orr and Stepenuck, 2004]. Currently, twenty-six states sponsor volunteer monitoring programs, and efforts are being made to enhance nationwide support for these programs [Overdevest, Orr and Stepenuck, 2004]. Some organizations use their volunteer-collected data to publish reports on the status of water quality in particular water bodies which are made available for public use or are used by state agencies for resource management decisions [Maine Lakes Report; Near Real-Time Lake Data; URI WW Data Available Online; URI WW Monitoring Data and Results; Yuba Shed; Maine Volunteer Lake Monitoring Program, 2013; Shilling, 2006].

Volunteers are passionate about water bodies due to their personal connections to water derived from recreational use, property ownership, or cultural significance [Addy et al., 2010]. This passion translates into a dedication to protect water resources. Through training and monitoring activities, volunteers can learn about water quality issues, how their actions affect the water, and what can be done to protect water bodies and human health. Volunteers often share what they have learned with others and become involved in management decisions [Addy et al., 2010], effectively meeting all three goals of citizen science: education, research, and stewardship.

\section{Assessing volunteer motivations}

Although volunteer motivations have been studied in many fields, few studies have been published on motivations that pertain specifically to participants in citizen science projects [Nov, Arazy and Anderson, 2014; Raddick et al., 2010]. Because citizen science projects are gaining popularity [Conrad and Hilchey, 2011; Dickinson and Bonney, 2012; SciStarter; Theobald et al., 2015], such projects raise new questions. How do citizen science volunteer motivations compare with volunteer motivations in other fields? What unique motivations might exist for volunteers in citizen science projects? Specifically, to what extent are volunteers motivated by the application and communication of the scientific data that they collect? How do such motivations vary with demographics and patterns of time commitment? This study illuminates motivations specific to citizen science volunteers so that managers can improve recruitment and retention, collection of data reliability, communication of results, and volunteer recognition. 
This study focused on eight organizations with volunteers that participate in a broad array of water quality monitoring activities including chemical tests, secchi disk clarity tests, and macroinvertebrate studies (Table 1). A web-based survey was designed to capture volunteer motivations, demographics, frequency and duration of volunteering, social interactions, and preferences for activities and recognition. The survey consisted of multiple choice and Likert-type questions with a five-point response format from "strongly disagree" to "strongly agree." Many questions regarding motivations and social interactions were designed to mirror questions, language, and insights found in previous studies [Asah and Blahna, 2012; Bell et al., 2008; Bruyere and Rappe, 2007; Jacobson, Carlton and Monroe, 2012; King and Lynch, 1998; Nov, Arazy and Anderson, 2014; Raddick et al., 2010;

Roggenbuck et al., 2001; Ryan, Kaplan and Grese, 2001]. Novel questions were also included to address gaps in the literature. Specifically, questions relating to the use of volunteer-collected data have not been found in previous studies, and types of recognition have only received minimal attention in previous studies. Only three types of recognition were quantified in the study by Roggenbuck et al. [2001]: certificates, a verbal or written "thank you," and awards banquet. This study quantifies several more types of reward including paraphernalia, volunteer appreciation event, and name recognition across multiple platforms.

The survey was open from February 18 to March 13, 2015. As a method to incentivize participation in the survey, all respondents who completed the survey had the option to be entered in a random drawing for one of ten subscriptions to National Geographic. Staff members of participating organizations sent the survey via email to their volunteer base followed by reminder emails. In total, the survey was emailed to 1,045 volunteers, 271 responses were received, and the overall response rate was $25.9 \%$. One organization, Maine Volunteer Lake Monitoring Program (VLMP), represented $48 \%$ of the total responses, which may be a source of bias. Another organization, University of Rhode Island Watershed Watch Program, comprised $27 \%$ of the total responses. A third organization, South Yuba River Citizens League, constituted $11 \%$ of the responses while the remaining five organizations comprised less than $4 \%$ each. For the purpose of this study, all respondents were considered to be citizen scientists because $95 \%$ of respondents reported "collect data or record observations" as a task that they perform when volunteering.

Results and discussion

\section{Demographics}

Respondents represented all ages from 21 years and older. Most survey respondents were over age $50(86 \%)$, the age group with the most responses was $60-69(37 \%)$, and thirteen respondents were over age $80(5 \%)$. The respondents were split fairly evenly between male (55\%) and female ( $44 \%) ; 1 \%$ preferred not to indicate gender. Most were well educated (35\% with a bachelor's degree and $45 \%$ with a graduate degree as highest completed degrees). A large portion of respondents were retired (45\%). About one-third were employed full-time (32\%) and one-sixth were employed part-time (17\%). Of the respondents that reported income, $84 \%$ earned at least half of the household income and $38 \%$ earned all of the household income. 
Table 1. Participating organizations and number of responses.

\begin{tabular}{|c|c|c|c|}
\hline \multicolumn{4}{|c|}{ Participating Organizations } \\
\hline Organization & Location & $\begin{array}{l}\text { Number of } \\
\text { volunteers } \\
\text { who were } \\
\text { emailed the } \\
\text { survey }\end{array}$ & $\begin{array}{c}\text { Number of } \\
\text { responses } \\
\text { received }\end{array}$ \\
\hline $\begin{array}{l}\text { Maine Volunteer Lake Monitoring } \\
\text { Program (VLMP) }\end{array}$ & $\begin{array}{l}\text { Maine: } \\
\text { statewide }\end{array}$ & 466 & 130 \\
\hline $\begin{array}{l}\text { University of Rhode Island Watershed } \\
\text { Watch Program (URIWW) }\end{array}$ & $\begin{array}{l}\text { Rhode Island: } \\
\text { statewide }\end{array}$ & 360 & 74 \\
\hline $\begin{array}{l}\text { South Yuba River Citizens League } \\
\text { (SYRCL) }\end{array}$ & $\begin{array}{l}\text { California: } \\
\text { Nevada City }\end{array}$ & 57 & 30 \\
\hline $\begin{array}{l}\text { North Pond Association of Maine } \\
\text { (NPA) }\end{array}$ & $\begin{array}{l}\text { Maine: Mercer, } \\
\text { Smithfield, } \\
\text { Rome }\end{array}$ & 15 & 10 \\
\hline $\begin{array}{l}\text { Nisqually River Education Project } \\
\text { (NREP) }\end{array}$ & $\begin{array}{l}\text { Washington: } \\
\text { Thurston } \\
\text { County }\end{array}$ & 49 & 10 \\
\hline $\begin{array}{l}\text { South Sound Global Rivers } \\
\text { Environmental Education Network } \\
\text { (GREEN) }\end{array}$ & $\begin{array}{l}\text { Washington: } \\
\text { Thurston } \\
\text { County }\end{array}$ & 24 & 7 \\
\hline Boquet River Association (BRASS) & $\begin{array}{l}\text { New York: } \\
\text { Elizabethtown }\end{array}$ & 4 & $5^{1}$ \\
\hline Stream Team & $\begin{array}{l}\text { Washington: } \\
\text { Thurston } \\
\text { County }\end{array}$ & 70 & 5 \\
\hline & Total: & 1045 & 271 \\
\hline
\end{tabular}

\section{Duration and frequency of volunteer activity}

Thirty percent of respondents were involved with their organization for more than 10 years, $21 \%$ involved one to three years, $21 \%$ involved four to six years, $16 \%$ involved for seven to ten years, and $12 \%$ involved for up to one year. ${ }^{1}$ A response bias may be indicated by the volunteers with greatest length of involvement who may also be more likely than newer volunteers to respond to survey requests from project coordinators. From this point forward, volunteers will be referred to as "new" or "veteran" on the continuum of involvement from "up to one year" (newest) to "more than 10 years" (most veteran). The term "longevity" will refer to a volunteer's length of involvement with their organization.

Nearly half of respondents (43\%) volunteered about two times per month. Those who attended events twice per month most often spent between 30 minutes and one hour (Figure 1). About $18 \%$ volunteered more frequently - at least once per week - and those volunteers most often spent one to two hours. Volunteers who

\footnotetext{
${ }^{1}$ Respondents took the survey in February and March of 2015. The group "up to one year" actually reflects up to 15 months of involvement because respondents who began volunteering with their organization in 2015 were grouped with respondents who began in 2014 .
} 
attended events less frequently than twice per month, tended to spend more time at each event - two to four hours. One-quarter of all respondents $(24 \%)$ spent between 30 minutes and one hour each time they volunteered, nearly one-third (29\%) spent between one and two hours, and one-third (33\%) spent between two and four hours. The fewest number of volunteers spent less than 30 minutes or more than four hours regardless of frequency. This evidence suggests that providing frequent opportunities to participate ( 2 or more per month) and varied event duration (between 30 minutes and 4 hours) is essential to volunteer retention, and perhaps the most popular events would occur 2 times per month for a duration between 30 minutes and 2 hours. Retaining volunteers with frequent opportunities to participate was also evidenced in one study [Ryan, Kaplan and Grese, 2001].

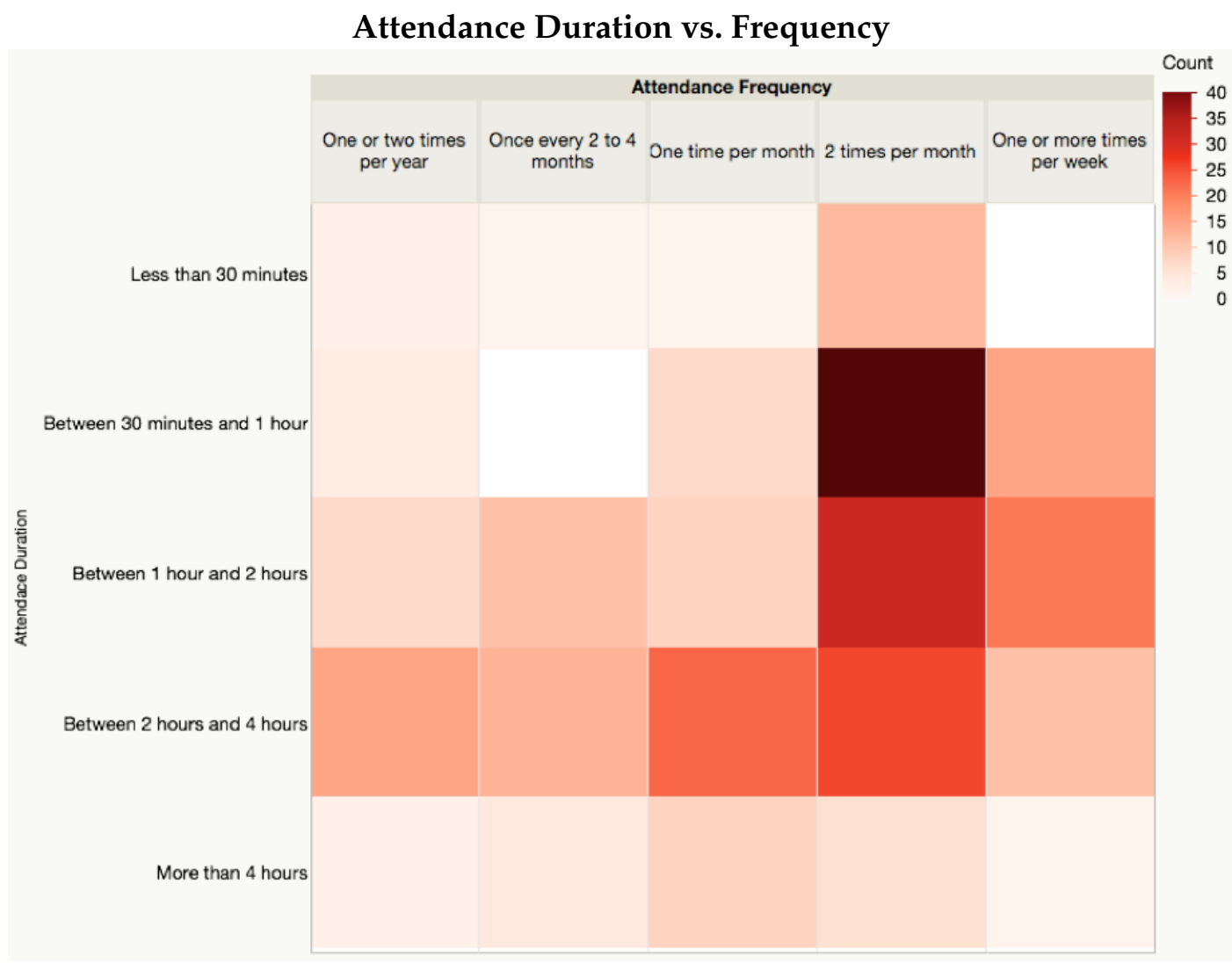

Figure 1. Heat map indicating response counts for attendance frequency (horizontal axis) versus duration (vertical axis). Darker colors represent more responses than lighter colors.

\section{Motivations to participate}

Respondents were asked to indicate their level of agreement with a series of 12 statements about reasons for volunteering (Figure 2). The results are similar to previous studies on environmental volunteer motivations with "helping the environment" as the strongest motivator and "advancing one's career" as the weakest motivator [Asah and Blahna, 2012; Bruyere and Rappe, 2007; Jacobson, Carlton and Monroe, 2012; King and Lynch, 1998; Roggenbuck et al., 2001; Ryan, Kaplan and Grese, 2001]. "To contribute to scientific knowledge" was the fourth strongest motivator in the present study, although this motivator was found explicitly in only one previous study on citizen science [Raddick et al., 2010] and 
only briefly mentioned in another [Rotman et al., 2014]. This motivator is examined more carefully below.

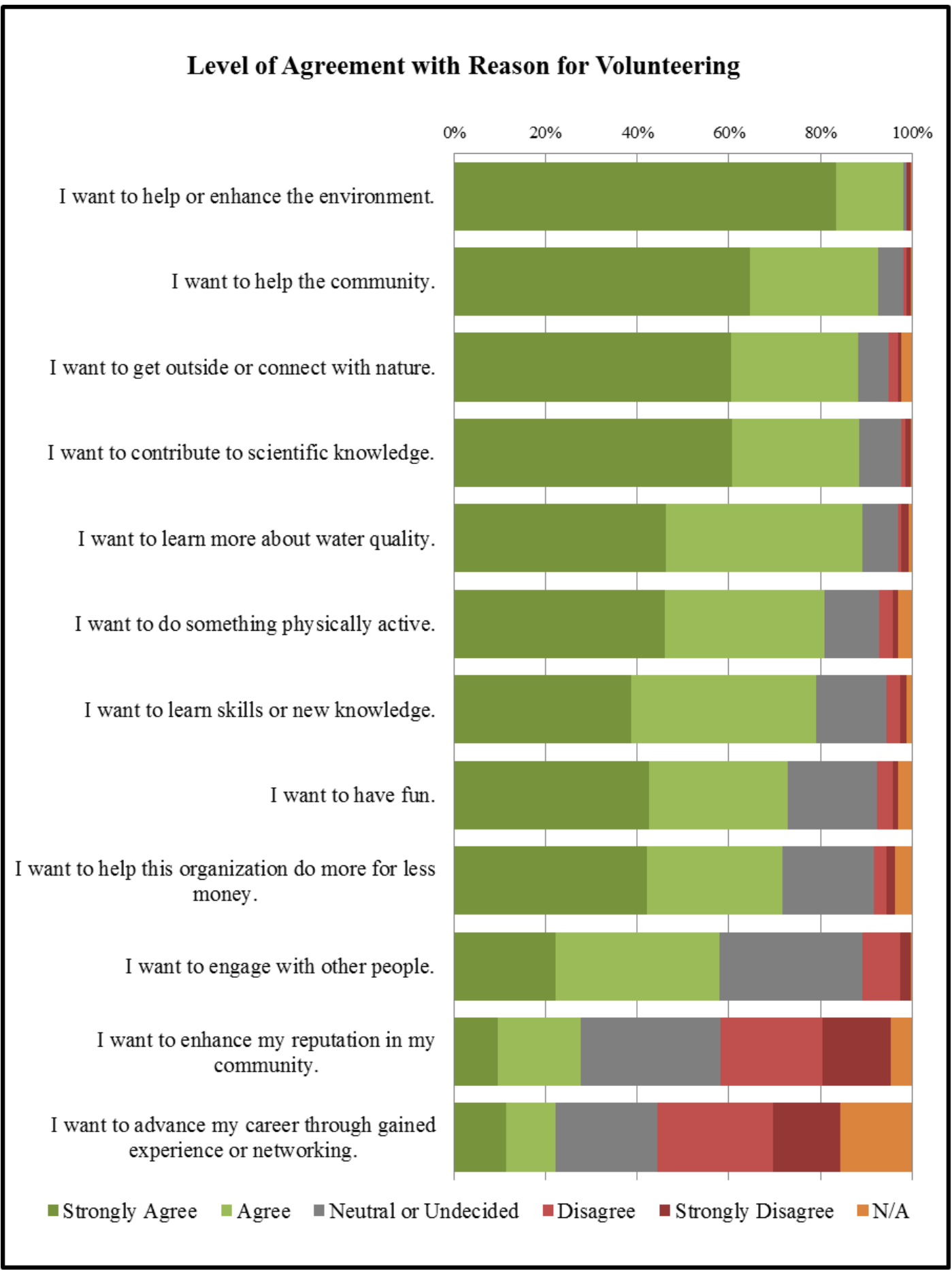

Figure 2. Frequency of responses for each motivation in order of strongest to weakest agreement. Green indicates agreement (darker green for "strongly agree"), gray represents "neutral or undecided", and red indicates disagreement (darker red for "strongly disagree"). Orange represents "N/A" (not applicable).

If veteran volunteers have different motivators than newer volunteers, this would be valuable information to incorporate in recruitment and retention campaigns. The mean rating of volunteer motivations was calculated for respondents in groups 
based on length of involvement with their organization: up to one year, one to three years, four to six years, seven to ten years, and more than ten years. For most motivations, very few differences were found between the newer and veteran volunteers. However, the motivators "enhance my reputation" and "advance my career" were rated higher by the newest volunteers (mean $=3.23$ and 3.38, respectively) than the most veteran volunteers (mean $=2.71$ and 2.58 , respectively), although these are still the lowest rated motivations of all the motivations for the newest volunteers.

To see if age influenced the importance of motivators, the mean rating of motivations for each age group was found. Younger volunteers rated the "career" motivation much higher than the other age groups. The mean ratings of "career" for the two youngest age groups, 20-29 and 30-39, were 4.33 and 3.56 respectively, while the mean rating for "career" by all respondents was only 2.75 . The "career" motivation is the sixth strongest motivator for the two youngest age groups, as opposed to the $12^{\text {th }}$ and weakest motivator for the population as a whole. Furthermore, the mean ratings for the "career" motivation decrease with increasing age groups. The mean rating for "I want to enhance my reputation in my community" was also higher for the youngest age group than older age groups. The mean for the youngest group was 3.56, while the mean for all respondents was only 2.84. Age groups did not reveal patterns in the other motivators. This may suggest that younger people are looking for opportunities to network with others in their field of work or their community.

Coordinators may want to recruit younger people with different messages than they would use to recruit older people, and they will need to change their messages over time as the new recruits age. While the differences are important to coordinators who want to recruit certain age groups, coordinators will also want to meet the needs of their most common volunteer, who are between ages 60 and 69 .

\section{Use of volunteer collected data}

As noted above, the fourth strongest motivator was contributing to scientific knowledge. This survey provided some resolution on this motivation that might benefit citizen science organizations. Although nearly all respondents agreed or strongly agreed that the data is used appropriately, about one-third also agreed or strongly agreed that more should be done with the data (Figure 3). Nearly all respondents indicated feeling good when data and/or results are shared with them and when environmental problems are identified and addressed because of the data collected. A little more than half agreed or strongly agreed that the data should be used for scientific publications.

Not surprisingly, many respondents who were strongly motivated by contributing to scientific knowledge also thought it was very important that the data be used for scientific publications (Figure 4). However, there were also a number of respondents strongly motivated by contributing to scientific knowledge that felt neutral or undecided about using the data for scientific publications. This pattern shows that a significant fraction of volunteers (29\%) view "scientific knowledge" as a more expansive category that scientific publications. This broader definition of scientific knowledge is apparent in the activities of the three organizations with the 


\section{Level of Agreement about How Data is Used by the Organization}

$\begin{array}{lllllllllll}0 \% & 10 \% & 20 \% & 30 \% & 40 \% & 50 \% & 60 \% & 70 \% & 80 \% & 90 \% & 100 \%\end{array}$

The data collected for this project is used appropriately.

More should be done with the data collected.

It is important to me that our data is used for scientific publications.

I feel good when data and/or results are shared with me.

I feel good when our data is used to determine if there are environmental problems.

I feel good when environmental problems are addressed because of our data.

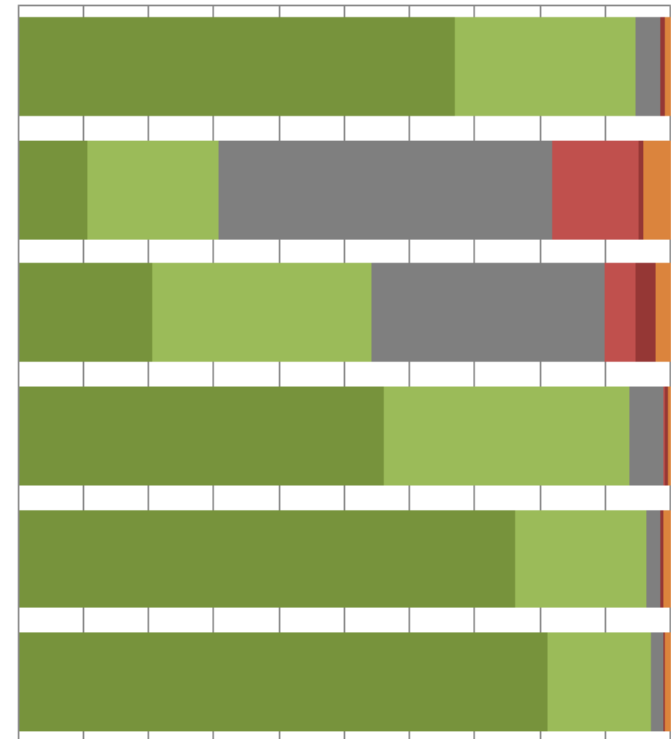

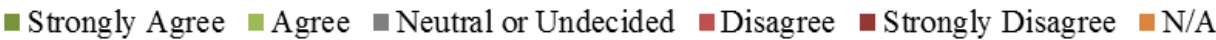

Figure 3. Frequency of responses for each statement about how data is used by the organization. Green indicates agreement (darker green for "strongly agree"), gray represents "neutral or undecided", and red indicates disagreement (darker red for "strongly disagree"). Orange represents "N/A" (not applicable).

most survey respondents: (1) Maine Volunteer Lake Monitoring Program (Maine VLMP), (2) University of Rhode Island Watershed Watch (URIWW), and (3) South Yuba River Citizens League (SYRCL). These three groups contributed 86.4\% of the total survey responses. All three groups make volunteer-collected data publicly available, however, there is no web evidence showing the inclusion of this data in peer-reviewed scientific publications.

The data collected by Maine VLMP is considered the "primary source of lake data in the state of Maine" [Maine Volunteer Lake Monitoring Program, 2013]. Maine VLMP produces an annual report (available online) that summarizes lake water quality and the status of invasive plants [Maine Lakes Report]. The report includes an appendix with a list of all volunteers, several photos, and a separate list recognizing those volunteers with 10 or more years of service [Maine Volunteer Lake Monitoring Program, 2013]. The organization also publishes near real-time water quality data for eleven lakes to provide the public with an overview on state lake health [Near Real-Time Lake Data].

The data collected by URIWW is used to assess and manage state water bodies by the Rhode Island Department of Environmental Management, "municipal governments, associations, consulting firms and residents" [URI WW Monitoring Data and Results]. Data is available online or by request and updates on bacteria are posted within one week of sampling [URI WW Data Available Online]. 


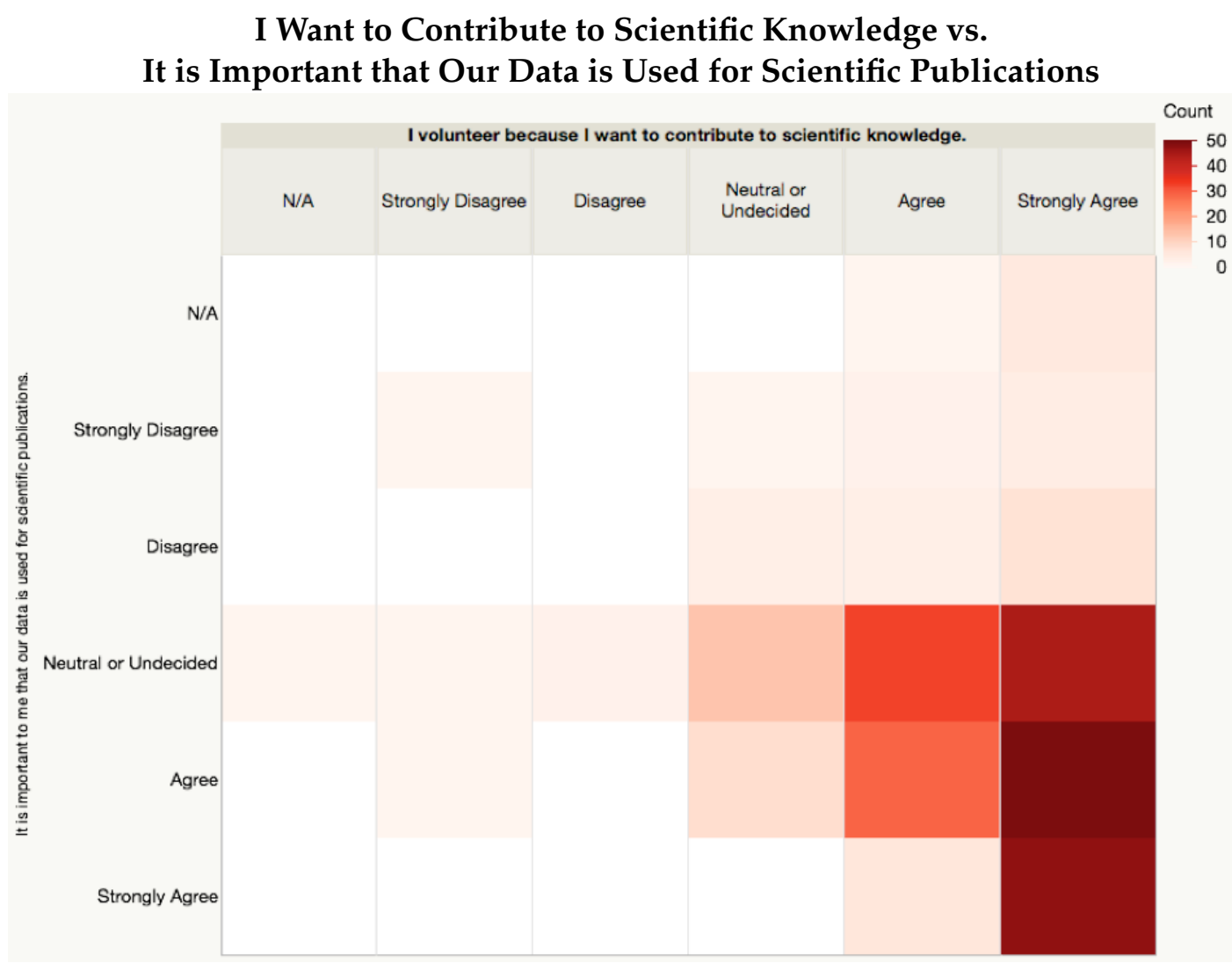

Figure 4. Heat map indicating response counts for level of importance that data is used for scientific publications (vertical axis) versus the participation motivator "I want to contribute to scientific knowledge" (horizontal axis). Darker colors represent more responses than lighter colors.

Data collected by SYRCL volunteers is used to inform SYRCL's restoration projects and advocacy campaigns about salmon habitat, dams, and hydropower [River Science]. The data was used to produce a report assessing the state of the Yuba River Watershed in 2006 [Shilling, 2006]. Data is also contributed to an ongoing project called Yuba Shed, which makes data, photos, maps, and tools available to the public online [Yuba Shed].

Based on these activities by the three groups contributing the majority of the responses for this survey, it would appear that volunteers value public data, ecosystem management, and environmental stewardship over scientific publications. Most volunteers who were strongly motived by contributing to scientific data felt neutral about the statement "more should be done with the data collected" (5). This may indicate that these volunteers were satisfied with how the organization uses data and thus supports the idea that appropriate use of data is a strong motivator for participation.

These results support the findings by Roggenbuck et al. [2001] and also show that volunteers want the outcomes of their labor to directly affect the issue they are monitoring. More importantly, they want to know how their efforts have made an impact. Volunteers felt more strongly about the results being shared with them than about the data being used for scientific publication. This reinforces claims made by other researchers that coordinators need to share results with their 


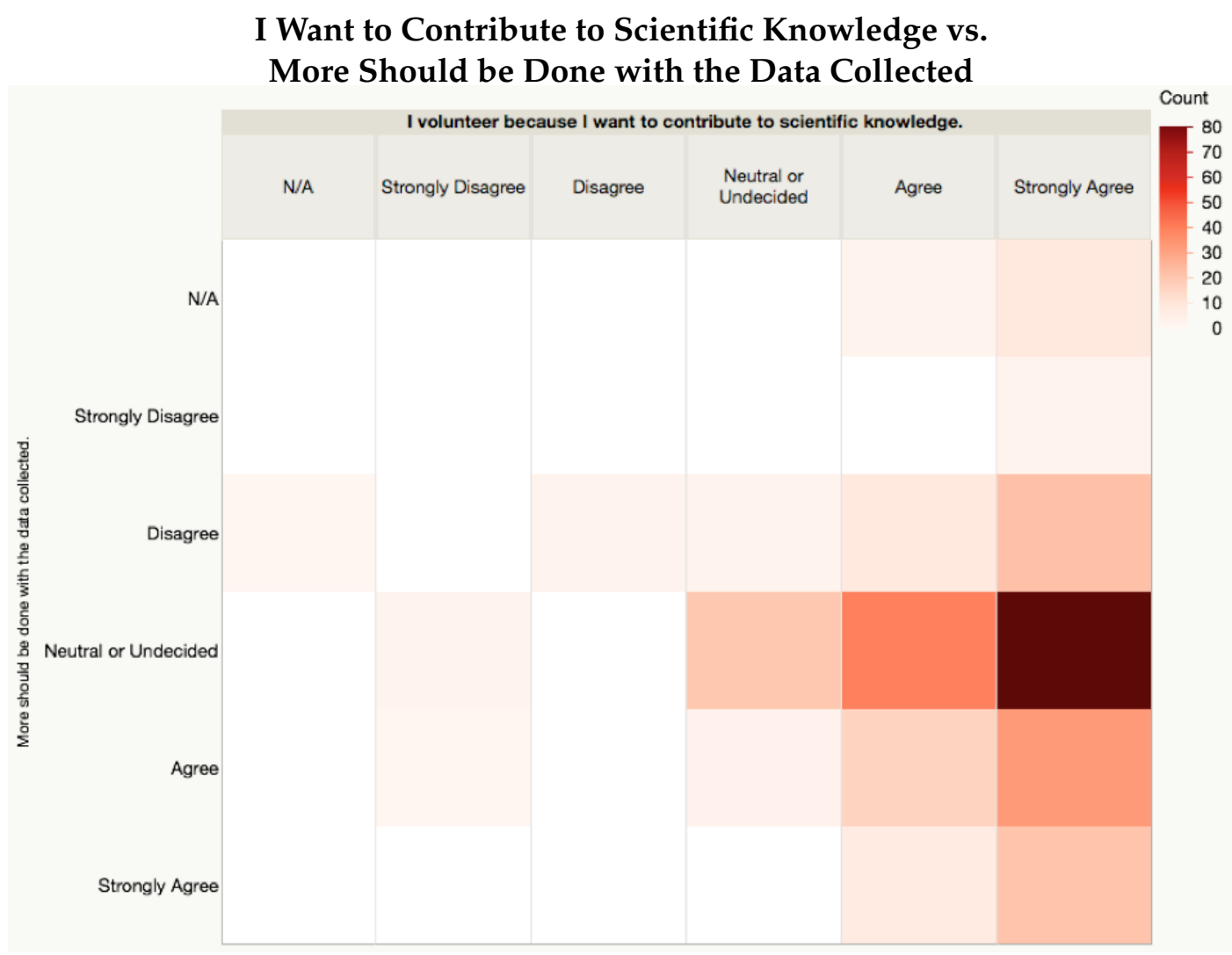

Figure 5. Heat map indicating response counts for level of importance that more should be done with the data (vertical axis) versus the participation motivator "I want to contribute to scientific knowledge"(horizontal axis). Darker colors represent more responses than lighter colors.

volunteers [Bell et al., 2008; Knoke, 1981; Nov, Arazy and Anderson, 2014; Roggenbuck et al., 2001; Rotman et al., 2014]. Further research could be done to explore the best or preferred methods for communicating results with volunteers.

\section{Social interactions}

Many respondents agreed or strongly agreed with statements that assessed motivations involving social interactions; however, these responses show that for many volunteers, learning in a social environment is very important (Figure 6). Respondents were asked to indicate their level of agreement with five statements about social interactions that completed the sentence "I volunteer because The statement with the highest level of agreement was "I like learning from others with more experience than me;" this was closely followed by "I like sharing my experience, knowledge, or expertise with other volunteers." Third highest was "I want to interact with like-minded people." The top three reasons each had at least $70 \%$ agreement. The two reasons with the lowest level of agreement were "I want to spend time with family or friends" (43\%) and "I want to meet new people" (42\%).

Because social motivations may differ for new or veteran volunteers, the means for each motivator across different lengths of involvement were compared. Newer and more veteran volunteers had close means for two social motivations: "I like sharing my experience, knowledge, or expertise with other volunteers" and "I want to 


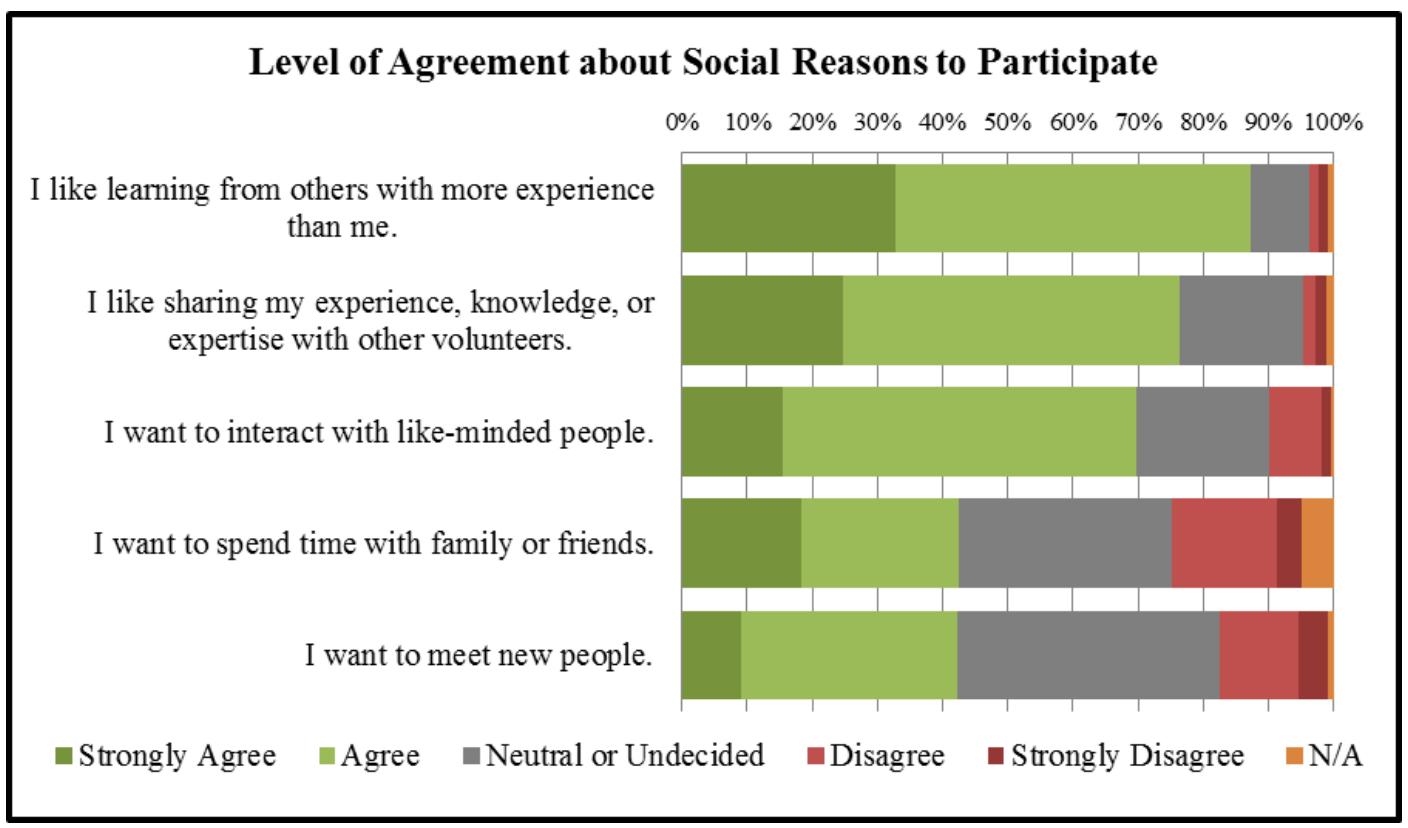

Figure 6. Frequency of responses for each statement about social interactions in order of strongest to weakest agreement. Green indicates agreement (darker green for "strongly agree"), gray represents "neutral or undecided", and red indicates disagreement (darker red for "strongly disagree"). Orange represents "N/A" (not applicable).

spend time with family and friends." Newer volunteers rated the other three social motivators higher than veteran volunteers: "I like learning from others with more experience than me," "I want to interact with like-minded people," and "I want to meet new people." The means for each motivator were also compared across different age groups. The most notable difference is in the last reason "I want to meet new people." Younger people rated this motivation higher than older people. There is no distinguishable pattern across the other motivators.

\section{Recognition and appreciation}

Much of the research on voluntarism advises coordinators to recognize the efforts of their volunteers and show them appreciation in some form [Bell et al., 2008; Jacobson, Carlton and Monroe, 2012; Roggenbuck et al., 2001; Rotman et al., 2014]. However, few quantitative studies assess what types of recognition are most meaningful to volunteers. Most respondents (84\%) reported having received some form of recognition. However, less than $40 \%$ agreed that receiving recognition is important. The most common response to this question was "neutral or undecided," and less than $10 \%$ indicated a preference not to receive any form of recognition. This is contradictory to one study that found the majority of volunteers preferred no recognition [Roggenbuck et al., 2001].

Respondents were asked to indicate how meaningful different forms of recognition were to them on a scale from "not meaningful at all" to "very meaningful." The highest rated form of recognition was a hand-written card (over $60 \%$ found this moderately meaningful or very meaningful); this was followed closely by a personalized email, a volunteer appreciation event, and name recognition in their 
organization's newsletter (Figure 7). The lowest rated type was name recognition in social media, such as Facebook or Twitter (about $20 \%$ found this moderately meaningful or very meaningful).

\title{
Importance of Different Forms of Recognition or Appreciation
}

\author{
$\begin{array}{llllllllllllllllllll}0 & 0 \% & 10 \% & 20 \% & 30 \% & 40 \% & 50 \% & 60 \% & 70 \% & 80 \% & 90 \% & 100 \%\end{array}$
}

Hand-written card

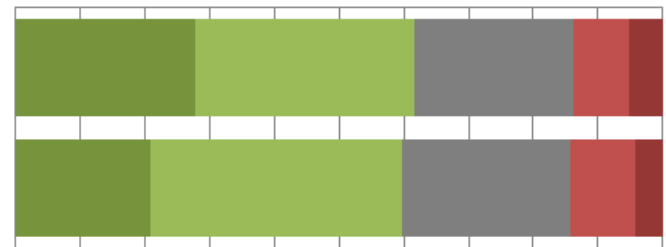

Volunteer appreciation event

Name recognition in this organization's newsletter

Paraphernalia - such as stickers, hats, or t-shirts from this organization

Certificate or token of appreciation

Name recognition in a scientific publication

Name recognition in social media - such as Facebook or Twitter
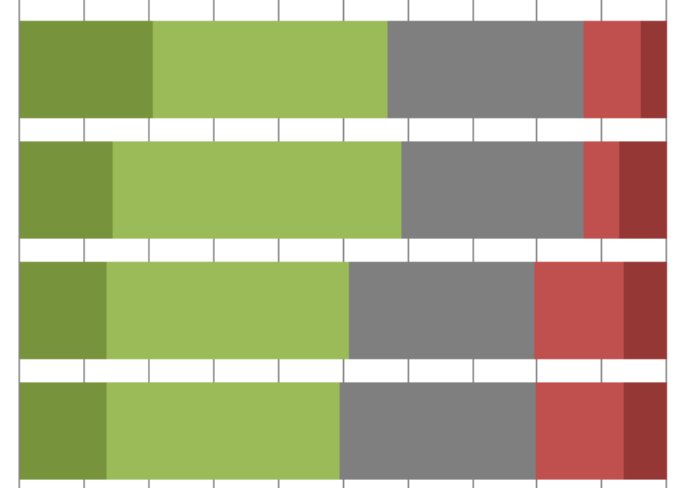
Facebook or Twitter

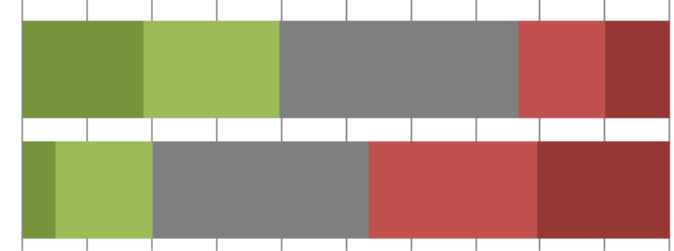

-Very meaningful $\quad$ Moderately meaningful $\quad$ Neutral or Undecided $\quad$-Not very meaningful $\quad$ Not meaningful at all

Figure 7. Frequency of responses for each form of recognition or appreciation in order of strongest to weakest agreement. Green indicates agreement (darker green for "strongly agree"), gray represents "neutral or undecided", and red indicates disagreement (darker red for "strongly disagree"). Orange represents "N/A" (not applicable).

Younger and older volunteers expressed different views about preferred forms of recognition. Younger respondents scored all forms of recognition higher than older respondents (Figure 8). Young people rated "name recognition" in both scientific publication and social media much higher than older people. Because younger volunteers placed more importance on advancing their career and enhancing their reputation than older volunteers, younger volunteers may care more about name recognition. The youngest age group rated "name recognition in a scientific publication" higher than all other forms of recognition (4.62). Such differences likely arise from each demographic group's respective career stage, but it might also reflect a generational shift. 


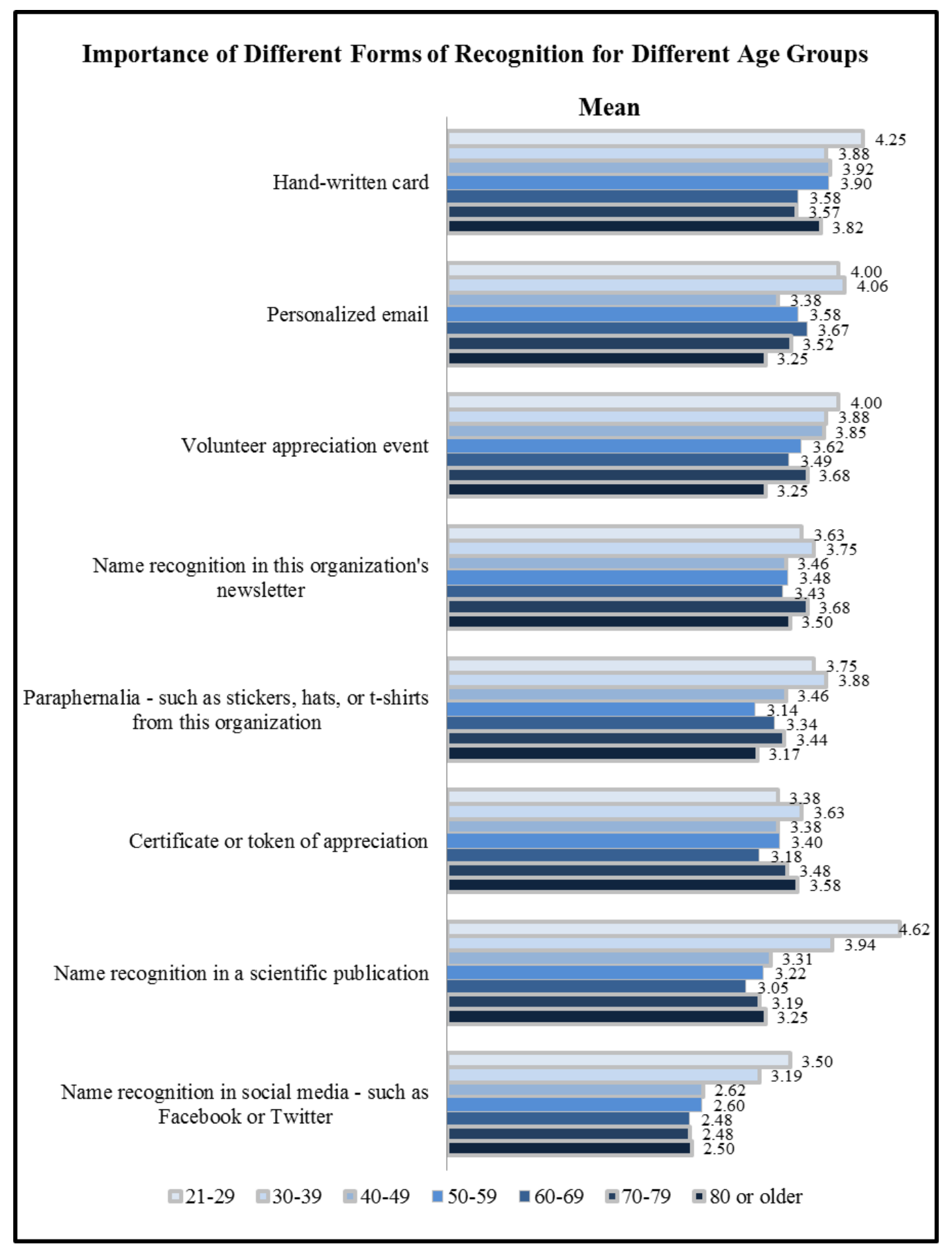

Figure 8. Mean importance of different forms of recognition or appreciation based on age and overall means. Responses were weighted accordingly: $1=$ "strongly disagree", 2 = "disagree", 3 = "neutral or undecided", 4 = "agree", and $5=$ "strongly agree", no weight was assigned to "N/A". 
This study found that the volunteer motivations for citizen science organizations that monitor water quality were quite similar to those identified for environmental stewardship organizations. Moreover, it identified a key motivator - "to contribute to scientific knowledge" - that has received minimal attention in previous studies of environmental volunteering. The importance of this motivator parallels a recent survey of volunteer motivations for members of Galaxy Zoo, a massive citizen science project to classify galaxies and other astronomical phenomena. Raddick et al. [2013] found that "contributing to scientific research" was by far the most important motivator for citizen scientists involved in Galaxy Zoo and the authors called for additional studies in other citizen science projects to determine whether such results could be generalized across citizen science projects.

This survey of water monitoring volunteers supports the importance of scientific contributions as a motivator in citizen science projects, but also provides evidence that this motivator exists alongside other very important motivators in the realm of environmental work. Motivations that serve the "values" function of the Volunteer Functions Inventory [Clary et al., 1998] are the strongest (to help the environment and community); closely followed by motivations serving the "ego protective" function (to get outside or connect with nature) and the "understanding" function (to contribute to scientific knowledge, to learn about water quality, to learn new skills or knowledge).

There was no difference in the importance of motivations based on gender. However, respondents' age and length of involvement played a role in the career motivation. Younger and newer volunteers rated "career" higher than older or veteran volunteers. The career motivator decreases in importance with increasing age. Even though the career motivator is rated lowest out of 12 for the populations as a whole, it is the sixth strongest for younger volunteers.

Because volunteers found "learning from others" and "sharing experiences with others" very important, coordinators should strive to create activities that are suitable for a range of experience and expertise levels. Creating an atmosphere of social learning can be achieved while incorporating group size preference by pairing or grouping more experienced volunteers with less experienced volunteers. Allowing the veteran volunteers to train the new volunteers is another option. Coordinators should note that younger and newer volunteers rated social motivations slightly higher than other groups, and an intellectual element in activities appears to be important.

\section{Communication and recognition}

Respondents overwhelmingly indicated feeling good when results were shared with them and even more so when environmental problems were identified and addressed because of their data. Most respondents were neutral about receiving recognition for their work, although it was important to at least $30 \%$. As a general pattern, this indicates that tangible results derived from the efforts of the volunteers are more important than any form of reward. It also shows that communicating results to the volunteers is more important than acknowledging a volunteer for their work. However, because other studies have revealed divergent results on the importance of recognition, this may be better explored through qualitative analysis 
of open-ended survey questions or focus group discussions. In addition, individual personality may play a large role in whether recognition is desired and in what form [Trachtman, 2015].

A hand-written card was perceived as the most meaningful form of recognition. Younger respondents rated all forms of recognition higher than older respondents, and the most important form of recognition to younger people was name recognition in a scientific publication, whereas this was the second least meaningful to the respondents overall. This may be indicative of either a generational or maturational shift. It could be that as people age, they care less about name recognition. However, it could indicate that the younger generation has different priorities, which may or may not persist as they age.

Coordinators should pay close attention to the pattern across age groups. When coordinators recruit young people, they could consider ways that their data can be published and make it known to the volunteers that they will receive acknowledgment in the publications. Coordinators also need to pay attention to the body of volunteers that are currently participating and make sure that they cultivate the motivations of those volunteers as well. Since most of the respondents are over 50 and place little importance on name recognition, coordinators will need to reward them differently, such as with a card or an appreciation event.

\section{Further research}

Although the fourth highest of the 12 motivators to participate was "I want to contribute to scientific knowledge," many respondents felt neutral about data being used for scientific publications. This set of responses raises interesting questions and avenues for further exploration: How do citizen scientists perceive or define scientific knowledge? Why are publications relatively unimportant to the volunteer and what form of scientific knowledge should the data take? This could be explored by asking volunteers their opinion on how their data should be used. Volunteers may perceive scientific publications as somewhat inaccessible and, since they value tangible results, perhaps the issue is more about the data being made publicly available so that it may be used to solve problems.

Volunteers place great value on results being shared with them, so the next step would be to improve methods to communicate this information. Do volunteers prefer to receive updates via email or newsletters? They might prefer a presentation that interprets the results; this would fulfill the "understanding" motivation and some volunteers may take this information and act as ambassadors by teaching other non-participants about stewardship.

Conflicting responses about social motivators indicated that this topic is difficult to address in a closed-ended questionnaire. For example, "I want to engage with other people" was important to $60 \%$ of respondents, and "I want to interact with like-minded people" was important to $70 \%$, but "to spend time with family and friends" and "to meet new people" were only important to $40 \%$. Individuals may be more motivated than they report by interpersonal relationships within the organization. For example, when friendships are developed, an individual may become more motivated to attend events knowing that they might see their friends 
there. However, this force may act on a level that is too subtle for an individual to be conscious of when taking a survey. Understanding how social interactions influence participation may require focus groups or participant observation.

Finally, coordinators would benefit greatly from more specific knowledge about how to acknowledge their volunteers and whether some individuals feel uncomfortable naming a specific reward because they are contributing their efforts mostly from a function of altruism and thus they feel that should not need a reward. Like social interactions, reward may act on a subtle level of consciousness, wherein receiving a reward makes the volunteer feel good, but this feeling may not arise to a level of awareness when the individual is taking a survey.

Despite the unanswered questions that arose from this study, the results provide clear directions for project coordinators which they can incorporate into the activities they offer, how they show appreciation to their volunteers, and how they craft messages to recruit and retain volunteers. Because water quality monitors represent an intersection between citizen science and environmental stewardship, this study will help coordinators in both fields to improve retention.

Addy, K., Green, L., Herron, E. and Stepenuck, K. (2010). Why Volunteer Water Quality Monitoring Makes Sense. Guide for Growing Extension Volunteer Monitoring Programs. Factsheet II. US Department of Agriculture. Washington, DC, U.S.A.: USDA — NIFA Volunteer Water Quality Monitoring National Facilitation Project. URL: http://www . usawaterquality . org/volunteer/pdf/Gu ideBook/Why_Makes_Sense_II.pdf.

Asah, S. T. and Blahna, D. J. (2012). 'Motivational functionalism and urban conservation stewardship: implications for volunteer involvement: Urban conservation stewardship'. Conservation Letters 5 (6), pp. 470-477. DOI: 10.1111/j.1755-263X.2012.00263.x.

Bell, S., Marzano, M., Cent, J., Kobierska, H., Podjed, D., Vandzinskaite, D., Reinert, H., Armaitiene, A., Grodzińska-Jurczak, M. and Muršič, R. (2008). 'What counts? Volunteers and their organisations in the recording and monitoring of biodiversity'. Biodiversity and Conservation 17 (14), pp. 3443-3454. DOI: $10.1007 / \mathrm{s} 10531-008-9357-9$.

Bruyere, B. and Rappe, S. (2007). 'Identifying the motivations of environmental volunteers'. Journal of Environmental Planning and Management 50 (4), pp. 503-516. DOI: $10.1080 / 09640560701402034$.

Clary, E. G., Snyder, M., Ridge, R. D., Copeland, J., Stukas, A. A., Haugen, J. and Miene, P. (1998). 'Understanding and assessing the motivations of volunteers: A functional approach.' Journal of Personality and Social Psychology 74 (6), pp. 1516-1530. DOI: 10.1037/0022-3514.74.6.1516.

Conrad, C. C. and Hilchey, K. G. (2011). 'A review of citizen science and community-based environmental monitoring: issues and opportunities'. Environmental Monitoring and Assessment 176 (1), pp. 273-291. DOI: $10.1007 / \mathrm{s} 10661-010-1582-5$.

Dickinson, J. L. and Bonney, R., eds. (2012). Citizen Science: Public Participation in Environmental Research. Ithaca, NY, U.S.A.: Cornell University Press. 
Jacobson, S. K., Carlton, J. S. and Monroe, M. C. (2012). 'Motivation and Satisfaction of Volunteers at a Florida Natural Resource Agency'. Journal of Park and Recreation Administration 30 (1), pp. 51-67. URL: http://js.sagamorepub.com/jpra/article/view/2542.

King, K. N. and Lynch, C. V. (1998). 'The Motivation of Volunteers in The Nature Conservancy-Ohio Chapter, a Non-Profit Environmental Organization'. The Journal of Volunteer Administration 16 (2), pp. 5-11.

Knoke, D. (1981). 'Commitment and Detachment in Voluntary Associations'. American Sociological Review 46 (2), pp. 141-158. DOI: 10.2307/2094975.

Maine Volunteer Lake Monitoring Program. Maine Lakes Report. URL: http://www . mainevlmp.org/maine-lake-report (visited on 2nd June 2015).

- Near Real-Time Lake Data. URL: http://www . mainevlmp.org/near-real-time-lake-data (visited on 2nd June 2015).

- (2013). Maine Lakes Report 2013. Auburn, ME, U.S.A.

Nov, O., Arazy, O. and Anderson, D. (2014). 'Scientists@Home: What Drives the Quantity and Quality of Online Citizen Science Participation?' PLOS ONE 9 (4). Ed. by J. Bar-Ilan, pp. 1-11. DOI: 10.1371/journal . pone. 0090375.

Overdevest, C., Orr, C. H. and Stepenuck, K. (2004). 'Volunteer stream monitoring and local participation in natural resource issues'. Human Ecology Review 11 (2), pp. 177-185. URL: http://ww . humanecologyreview.org/pastissues/her112/o verdevestorrstepenuck.pdf.

Raddick, M. J., Bracey, G., Gay, P. L., Lintott, C. J., Murray, P., Schawinski, K., Szalay, A. S. and Vandenberg, J. (2010). 'Galaxy Zoo: Exploring the Motivations of Citizen Science Volunteers'. Astronomy Education Review 9 (1). DOI: 10.3847/AER2009036.

Raddick, M. J., Bracey, G., Gay, P. L., Lintott, C. J., Cardamone, C., Murray, P., Schawinski, K., Szalay, A. S. and Vandenberg, J. (2013). 'Galaxy Zoo: Motivations of Citizen Scientists'. Astronomy Education Review 12 (1). DOI: 10.3847/AER2011021.

Roggenbuck, J. W., Haas, S. C., Hall, T. E. and Hull, R. B. (2001). Motivation, Retention, and Program Recommendations of Save Our Streams Volunteers. Blacksburg, VA, U.S.A.: Virginia Water Resources Research Center at Virginia Polytechnic Institute and State University. URL: https://vtechworks.lib.vt.edu/handle/10919/49465.

Rotman, D., Hammock, J., Preece, J., Hansen, D., Boston, C., Bowser, A. and He, Y. (2014). 'Motivations Affecting Initial and Long-Term Participation in Citizen Science Projects in Three Countries'. In: iConference 2014 Proceedings. iSchools, pp. 110-124. DOI: $10.9776 / 14054$.

Ryan, R. L., Kaplan, R. and Grese, R. E. (2001). 'Predicting Volunteer Commitment in Environmental Stewardship Programmes'. Journal of Environmental Planning and Management 44 (5), pp. 629-648. DOI: 10.1080/09640560120079948.

SciStarter. Citizen Science. URL: http://scistarter.com/page/Citizen\%20Science.html (visited on 2nd January 2015).

Shilling, F. (2006). State of the Yuba: An Assessment of the Yuba River Watershed. Nevada City, CA, U.S.A.

Shirk, J. L., Ballard, H. L., Wilderman, C. C., Phillips, T., Wiggins, A., Jordan, R., McCallie, E., Minarchek, M., Lewenstein, B. V., Krasny, M. E. and Bonney, R. (2012). 'Public Participation in Scientific Research: a Framework for Deliberate Design'. Ecology and Society 17 (2). DOI: 10.5751/ES-04705-170229. 
South Yuba River Citizens League. River Science. URL: http://yubariver .org/our-work/river-science/ (visited on 2nd June 2015).

Theobald, E. J., Ettinger, A. K., Burgess, H. K., DeBey, L. B., Schmidt, N. R., Froehlich, H. E., Wagner, C., HilleRisLambers, J., Tewksbury, J., Harsch, M. A. and Parrish, J. K. (2015). 'Global change and local solutions: Tapping the unrealized potential of citizen science for biodiversity research'. Biological Conservation 181, pp. 236-244. DOI: 10.1016/j . biocon.2014.10.021.

Trachtman, M. (March 2015). Volunteer Management: Recruiting, Retention, and Performance. Olympia, WA, U.S.A.: LOTT's WET (Water Education and Technology) Science Center.

University of Rhode Island, Watershed Watch. Data Available Online. URL: http://www.uri.edu/ce/wq/ww/data/DataTable.htm (visited on 2nd June 2015).

- Monitoring Data and Results. URL: http://www.uri.edu/ce/wq/ww/Data.htm (visited on 2nd June 2015).

Volunteer Water Monitoring and Master Naturalist Programs in the US (2013). URL: http://www . usawaterquality.org/volunteer/VolunteerMonPrograms/index .html (visited on 22nd January 2015).

Yuba Shed. The Yuba River Watershed Information System. URL: http://yubashed.org/ (visited on 2nd June 2015).

Author

Bethany Alender recently completed her Master of Environmental Studies at The Evergreen State College in Olympia, WA, and she currently works as the Outreach Coordinator for the Beaver Watershed Alliance in Northwest Arkansas. Her passion is to connect people to their environment and her research focuses on volunteers in citizen science and environmental stewardship. She also studies water conservation, biodiversity, and ecosystem services through the lens of outreach and communication. E-mail: bethany.alender@gmail.com.

\section{How to cite}

Alender, B. (2016). ‘Understanding volunteer motivations to participate in citizen science projects: a deeper look at water quality monitoring'. JCOM 15 (03), A04.

This article is licensed under the terms of the Creative Commons Attribution - NonCommercial NoDerivativeWorks 4.0 License.

ISSN 1824 - 2049. Published by SISSA Medialab. http:/ /jcom.sissa.it/. 